\title{
Relato Final do VII Encontro do Fórum Nacional de Cursos de Geologia*
}

São Paulo - Campinas - Rio Claro (SP), 28 a 31 de maio de 2007

\author{
Lucia Fantinel ${ }^{1}$ (UFMG) \\ Valdecir de Assis Janasi (USP) \\ José Fernando Pina Assis (UFPA) \\ Celso Dal Ré Carneiro (Unicamp)
}

*Este documento deve ser referido conforme abaixo:

Fantinel L., Janasi V.A., Assis J.F.P., Carneiro C.D.R. 2008. Relato Final do VII Encontro do Fórum Nacional de Cursos de Geologia. São Paulo-Campinas-Rio Claro, junho de 2007. Terræ Didatica, 4(1):81-84. <http:// www. ige.unicamp.br/terraedidatica/>

${ }^{1}$ Texto elaborado pelo profs. Lucia Fantinel e Fernando Pina a partir do registro diário das anotações feitas pelos vários coordenadores de seção do evento além das informações e citações fornecidas verbalmente pelos participantes do encontro.

\section{INTRODUÇÃO}

O VII Encontro do Fórum Nacional de Cursos de Geologia foi promovido entre os dias 28 a 31 de maio de 2007, nas cidades de São Paulo, Campinas e Rio Claro, pelas seguintes entidades: Universidade de São Paulo (USP), Universidade Estadual de Campinas (Unicamp), Universidade Estadual Paulista "Júlio de Mesquita Filho" (UNESP) e Sociedade Brasileira de Geologia (SBG). O VII Encontro aconteceu nos institutos aos quais estão vinculados os cursos de Geologia das três instituições paulistas. Estiveram presentes os seguintes representantes de cursos de Geologia:

1. Rommulo Conceição (Univ. Federal do Rio Grande do Sul/ UFRGS);

2. Gérson Fauth (Univ. do Vale do Rio dos Sinos/ UNISINOS);

3. Fernando Mancini (Univ. Federal do Paraná/ UFPR);

4. Valdecir de Assis Janasi (Univ. de São Paulo/ USP; Presidente da Comissão de Graduação); Excelso Ruberti (Coordenador do curso de Geologia, USP);

5. Maurício Compiani (Univ. Est. de Campinas/ UNICAMP);

6. Washington B. Leite Júnior (Univ. Est. Paulista/ UNESP);

7. Emilio Velloso (Chefe de Depto; Univ. Federal do Rio de Janeiro/ UFRJ);

8. Beatriz Paschoal Duarte (Univ. do Estado do Rio de Janeiro/ UERJ);

9. Lúcia Fantinel (Univ. Federal de Minas Gerais/ UFMG);

10. Messias Gilmar de Menezes (Univ. Federal de Ouro Preto/ UFOP);

11. Paulo Fortes (Univ. Federal do Espírito Santo/ UFES);

12. Carlos Humberto da Silva (Univ. Federal de Mato Grosso/ UFMT);

13. Harrizon Lima de Almeida (Univ Federal da Bahia/ UFBABarreiras);

14. Vanildo Pereira da Fonseca (Univ. Federal do Rio Grande do 
Norte/ UFRN);

15. Wellington Silva Filho (Univ. Federal do Ceará/ UFC);

16. José Fernando Pina Assis (Univ. Federal do Pará/ UFPA);

17. José Roberto Alecrim (Univ. Federal do Amazonas/ UFAM).

O plenário totalizou a presença de 17 (dezessete) dos 23 (vinte e três) cursos de Geologia do Brasil, identificados por suas respectivas coordenações, vice-coordenações e/ou representações indicadas. Adicionalmente, teve a participação do Prof. Paulo Cesar Boggiani, Coordenador da Licenciatura em Geociências e Educação Ambiental da USP) e da Executiva Nacional de Estudantes de Geologia/ Enege, respresentada por Maurício Borba.

Também participaram coordenadores associados, diretores de unidades, docentes e estudantes dos Cursos de Geologia das três universidades patrocinadoras do evento. Estiveram ausentes os representantes dos Cursos de Geologia das Universidades Federais da Bahia (Salvador), Pernambuco, Sergipe, Brasília, Marabá e Rural do Rio de Janeiro.

Durante três dias foram colocadas em pauta questões que afetam a operacionalização e o desempenho acadêmico dos cursos de Geologia do país, cujos resultados estão sintetizados neste relato, elaborado a partir dos dados coletados pelo presidente do Fórum.

O presente relato do encontro expõe sinteticamente os temas discutidos e as principais conclusões e deliberações.

\section{TEMAS APRESENTADOS}

\section{Dia 28 de maio, segunda-feira, Instituto de Geociências da USP, São Paulo-SP}

-Palestras

Avaliação dos Cursos de Geologia pelo Sistema Nacional de Avaliação do Ensino Superior, por Lúcia Maria Fantinel (UFMG, Presidente do Fórum).

Proposta: Avaliação dos Cursos de Graduação é um procedimento utilizado pelo MEC para o reconhecimento ou renovação (de reconhecimento) dos cursos de graduação, conforme estabelece a Lei de Diretrizes e Bases da Educação Superior, para o controle da qualidade do ensino oferecido pelas IES. A exposição visa apresentar a matriz orientadora do processo avaliativo e os indicadores das categorias didático-pedagógica, técnico-administrativo e de instalações físicas que compõem a avaliação e, assim, subsidiar a discussão sobre esse processo.

Formação de educadores em Geociências - o que priorizar?, por Paulo César Boggiani (USP, Coordenador do Curso de Licenciatura em Geociências e Educação Ambiental do IG-USP).

Proposta: A primeira turma do curso de Licenciatura em Geociências e Educação Ambiental do IG-USP deve se graduar em 2007. A palestra focalizará a estrutura do curso, as alterações que se mostraram necessárias a partir da experiência acumulada no seu desenvolvimento, e uma visão sobre as perspectivas profissionais do egresso. Será também uma oportunidade de discutir os principais conceitos e temas em geociências que devem ser abordados em um curso para educadores.

\section{-Mesa-Redonda}

\section{Diretrizes Curriculares dos cursos de Geologia}

Organização: Valdecir de Assis Janasi, Marcelo Monteiro da Rocha.

Proposta: Diferentemente da grande maioria das áreas de formação universitária, as Diretrizes Nacionais Curriculares para os cursos de Geologia não foram aprovadas até o momento no Conselho Nacional de Educação. Um grande esforço empreendido em encontros anteriores do Fórum Nacional de Cursos de Geologia aprovou, em 2001, proposta de Diretrizes, que foi encaminhada ao MEC, mas desde então não há informações sobre o andamento do processo, que muito provavelmente está parado, por motivos desconhecidos. A falta de diretrizes aprovadas tem consequências graves para a organização de novos currículos, para reformulações dos currículos já existentes, e para o diálogo com os organismos que regulamentam o exercício profissional. A Mesa Redonda propõe uma reflexão sobre as consequências da ausência de diretrizes curriculares para a profissão, e sobre estratégias a serem seguidas para a sua aprovação junto ao CNE-MEC.

Convidados: O Prof. Celso Dal Ré Carneiro (IG-UNICAMP) expôs sobre o histórico da elaboração e encaminhamento das Diretrizes Curriculares pelo Fórum, seguida de apresentações da estrutura dos cursos de Graduação em Geologia criados em anos recentes (UFPA-Marabá, pelo 
Prof. José Fernando Pina Assis, UFES, pelo Prof. Paulo Fortes; a confirmar apresentações sobre os cursos da UFS e UFBA-Barreiras). Para atuar como debatedores, foram convidados um Representante do CNE-MEC, o Presidente da SBG, Prof. Rômulo Machado, e colegas coordenadores de curso.

-Painéis

A estrutura dos cursos de Geologia do Brasil

Em paralelo à Mesa Redonda sobre Diretrizes Curriculares, ocorreu exposição de painéis com a apresentação das características gerais dos diversos cursos de Geologia do país.

\section{Dia 29 de maio, terça-feira, Instituto de Geociências da USP, São Paulo-SP}

-Mesas-Redondas

Atribuições Profissionais do Geólogo e a Resolução 1010 do Confea

Organização: Excelso Ruberti, Paulo R. Santos, Flávio Rogério da Silva.

Proposta: A recém-aprovada Resolução 1010 do Confea altera de modo significativo a atribuição de títulos e competências a profissionais geólogos. A discussão focalizou as características gerais da Resolução e detalhamentos recentes que especificam a sua aplicação aos novos diplomados. Os convidados debatedores e a platéia tiveram oportunidade de discutir as consequências da Resolução para a estratégia de formação de geólogos.

Convidados: conferencista, Nivaldo Bósio (Crea/Confea) e debatedores: Elias Daitx (Unesp), Lúcia Maria Fantinel (UFMG, Presidente do Fórum), Emílio Velloso Barroso (UFRJ), Rômulo Machado (Presidente da SBG)

O desafio da viabilização das aulas de campo nos cursos de Geologia

Organização: Ginaldo Campanha, A. Romalino Fragoso-César.

Proposta: A viabilização de aulas de campo em cursos de Geologia é um desafio que se apresenta a todos os coordenadores de curso, em vista da escassez de recursos, muitas vezes vinculada às dificuldades de demonstrar a órgãos de gerenciamento a necessidade de apoio financeiro para essas atividades. Foram apresentados relatos de experiências recentes enfrentadas em diferentes cursos de graduação; citaram instituições e empresas de geologia que oferecem diferentes formas de apoio a essas atividades, expondo sua visão do problema, de modo a contribuir para a identificação de soluções.

Convidados: Luis Guilherme Knauer (Centro de Geologia Eschwege- UFMG), Ricardo Latge (Petrobras), Agamenon S.L. Dantas (Diretor-Presidente da CPRM), colegas coordenadores de curso.

-Painéis e Palestra

A divulgação dos cursos de Geologia no Brasil

Em paralelo à Mesa Redonda sobre Viabilização de aulas de campo, ocorreu exposição de painéis sobre divulgação dos cursos de Geologia no Brasil, organizados por alunos do IGc-USP, IG-UNESP, IG-UNICAMP. Às 17:30 h houve exposição oral sobre o tema.

\section{Dia 30 de maio, quarta-feira, Instituto de Geociências da UNICAMP, Campinas-SP. (Deslocamento para Campinas, em ônibus do IGC- USP)}

-Mesa-Redonda

Os cursos de Geologia Introdutória no currículo de Geologia

Organização: Maurício Compiani, Paulo Boggiani.

Apresentações: Celso Dal Ré Carneiro e Pedro W. Gonçalves $A$ disciplina Sistema Terra na UNICAMP; Lucia M. Fantinel A experiência de Geologia Introdutória na UFMG

•Reunião

Fechamento do Documento Final do Fórum

Deslocamento para Rio Claro, em ônibus da UNICAMP

Comemoração do Dia do Geólogo (sede social da Associação dos Servidores da Faculdade de Filosofia - ASFAFI, Rio Claro)

Organização: Nelson Angeli, Washington Barbosa Leite Jr., Alexandre Francisco Petolchckny

\section{Dia 31 de maio, quinta-feira, IGCE-UNESP, Rio Claro-} SP

-Palestra e Discussão

\section{Geoturismo e Geoparques}

Organização: Washington Barbosa Leite Jr..

Convidada: Mariselma Ferreira Zaine, que proferiu palestra sobre Patrimônios Naturais e História Geológica da Região de Rio Claro-SP.

-Excursão 
Varvito de Itu - Rocha Moutonnée de Salto (SP): Geoturismo em Geoparques

Guias: José Alexandre de Jesus Perinotto, Norberto Morales e Mariselma Ferreira Zaine.

Retorno dos participantes para São Paulo (aeroporto e USP): Dia 1 de junho, saída às 8:00h, ônibus do IGCE-UNESP

\section{DELIBERAÇÕES}

Deliberações do VII Fórum Nacional de Cursos de Geologia, São Paulo, Campinas e Rio Claro, 28 a 31 de maio de 2007.

1. Referendar a Proposta de Diretrizes Curriculares Nacionais para os cursos de Graduação em Geologia encaminhada pelo Fórum ao MEC em 2001, alterando a carga horária mínima para 3.600h e a duração mínima para 5 anos, e estimulando as Instituições de Ensino Superior a fazer gestões junto ao Conselho Nacional de Educação para que o documento seja apreciado com urgência;

2. Apoiar a implantação definitiva dos novos cursos de geologia (UFPA-Marabá, UFBA-Barreiras, UFS-Aracaju e UFES-Alegre), solicitando aos órgãos competentes que se comprometam com a garantia de infra-estrutura e recursos humanos necessários ao seu funcionamento com qualidade. Defender a melhoria dos cursos já existentes que apresentam carências nessas mesmas questões;

3. Recomendar à Sociedade Brasileira de Geologia que apóie, junto ao Congresso Nacional, a aprovação do Projeto de Lei № 4796 de 2005, que regula o exercício profissional de Geofísico, e que consolida as atividades técnicas atualmente exercidas pelos geólogos nas áreas de: a) prospecção e projetos de locação, perfuração, captação e operação de sistemas de produção de água mineral e de água subterrânea; b) projetos de locação e perfuração de poços e sistemas de produção de petróleo e gás natural; c) estudos e trabalhos geotécnicos relacionados a rochas ou subsolo; d) elaboração de laudos de auditoria, impacto, gestão, proteção e recuperação do meio ambiente físico da superficie ou subterrâneo, e e) lavra e aproveitamento das substâncias minerais de que dispõe a Lei n. ${ }^{\circ} 6.567$ de 24 de setembro de 1978;

4. Fazer uma avaliação imediata da realidade das aulas de campo nos diversos cursos de Geologia e Engenharia Geológica, em termos quantitativos, qualitativos e de custos envolvidos, para compartilhar experiências e como subsídio para nortear gestões das IES junto às reitorias e garantir a execução com qualidade dessas atividades;

5. Recomendar que seja dada maior atenção à disciplina introdutória ao curso de Geologia e que se procure organizá-la com enfoque para ciência sistêmica do Planeta Terra (Sistema Terra), no sentido de desenvolver no aluno o raciocínio geológico de forma motivadora, indutiva e investigativa;

6. Recomendar que seja dada maior importância e atenção às disciplinas de caráter de Geologia Geral, ministradas para os demais cursos de Graduação, no sentido de ampliar a divulgação e demonstrar a importância das Geociências para a Sociedade;

7. Realizar o VIII Encontro do Fórum, no primeiro semestre de 2008, no Estado de Minas Gerais, em Ouro Preto e Belo Horizonte, nas dependências da UFOP e da UFMG;

8. Reorganizar a Comissão Diretora do Fórum, em atendimento ao Estatuto do Fórum Nacional de Cursos de Geologia, com a eleição do prof. Messias Gilmar de Menezes (UFOP) para Coordenador de Reuniões e do Prof. Rommulo Conceição (UFRGS) para Secretário;

9. Apoiar as iniciativas da comunidade acadêmica e técnico-científica em prol da recuperação e adequada manutenção dos parques de Itu e Salto, em São Paulo.

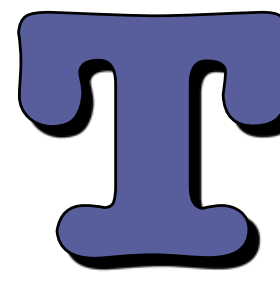

ISSN 1679-2300

\section{GEOSCIENCES • GEOGRAPHY • ENVIRONMENT}

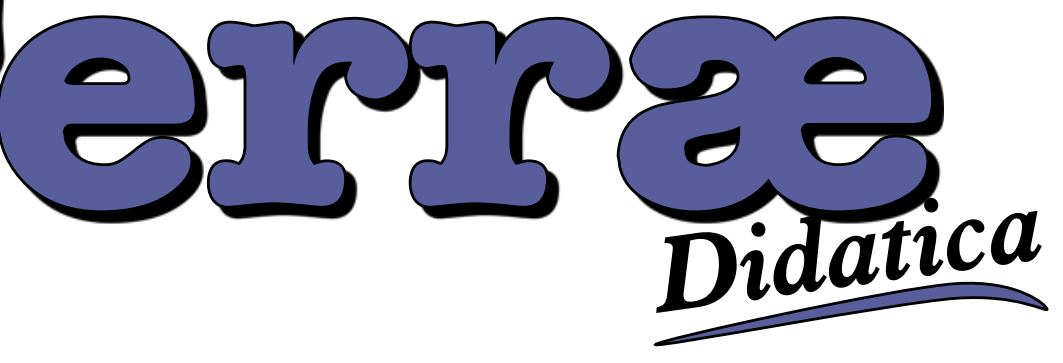

